\title{
A TERRA EM PANDEMIA: POVOS INDÍGENAS BRASILEIROS E SUAS (DERRADEIRAS?) INFÂNCIAS ${ }^{1}$
}

\author{
Lea Tiriba ${ }^{2}$ \\ Christiana C. Profice ${ }^{3}$ \\ Miguel T. Schlesinger ${ }^{4}$
}

\section{Resumo}

Inscrito no sofrimento da atual pandemia causada pelo coronavírus, este texto traz reflexões sobre relações entre seres humanos e natureza, sobretudo em referência aos povos originários do Brasil, com atenção especial voltada às suas infâncias. Tratamos conceitualmente da dicotomia natureza-humano, própria de nossa cultura ocidental, sob a ótica crítica da ecologia política e na busca de aproximação com teóricos da biofilia e da noção de sociobiodiversidade. A partir da percepção de proximidade entre as visões de mundo de Spinoza e de povos originários brasileiros, afirmamos a necessidade de aprender com os povos indígenas a cuidar das crianças e, simultaneamente, do planeta.

Palavras-chave: pandemia, povos originários, infâncias

\section{LA TIERRA EN PANDEMÍA: PUEBLOS INDÍGENAS Y SUS (ÚLTIMAS?) INFANCIAS}

\section{Resumen}

Inscrito en el sufrimiento de la pandemia actual causada por el coronavirus, este texto trae reflexiones sobre las relaciones entre los seres humanos y la naturaleza, especialmente en referencia a los pueblos originarios de Brasil, con especial atención a sus infancias. Tratamos conceptualmente con la dicotomía naturaleza-humano, típica de nuestra cultura occidental, bajo la perspectiva crítica de la ecología política y en la búsqueda de aproximación con los teóricos de la biofilia y de la sociobiodiversidad. Con base en la percepción de proximidad entre las visiones del mundo de Spinoza y de los pueblos originarios brasileños, afirmamos la necesidad de aprender de los pueblos indígenas para cuidar a los niños y, simultáneamente, del planeta.

Palabras clave: pandemia, pueblos originarios, infâncias

\section{EARTH IN PANDEMIA: BRAZILIAN INDIGENOUS PEOPLES AND (LAST?) CHILDHOODS.}

\section{Abstract}

Inscribed in the suffering of the current pandemic caused by the coronavirus, this text brings reflections about the relationships between human beings and nature, especially concerned with native peoples of Brazil, with special attention to their childhoods. We deal conceptually with the nature-human dichotomy, typical of our Western culture, from the critical perspective of political ecology and searching approximation with theorists of biophilia and the notion of socio biodiversity. Based on the perception of proximity between the worldviews of Spinoza and native Brazilian people, we affirm the need to learn from indigenous peoples to take care of children and, simultaneously, the planet.

Keywords: pandemic, Brasilian native people, childhood.

1 Artigo recebido em 02/06/2020. Primeira avaliação em 15/06/2020. Segunda avaliação em 18/06/2020. Aprovado em 29/07/2020. Publicado em 25/09/2020.

DOI: https://doi.org/10.22409/tn.v18i37.42988.

${ }^{2}$ Doutora em Educação pela Pontifícia Universidade Católica do Rio de Janeiro (PUC-Rio) - Brasil. Professora da Escola de Educação e do Programa de Pós Graduação em Educação (PPGEdu) da Universidade Federal do Estado do Rio de Janeiro (UNiRIO) - Brasil. E-mail: tiribalea@gmail.com ORCID: 000-0001-9508-5980

Lattes: http://lattes.cnpq.br/9891951792233220

${ }^{3}$ Doutora em Psicologia pela Universidade Federal do Rio Grande do Norte (UFRN) - Brasil. Professora do Programa de Pós-Graduação em Desenvolvimento Regional e Meio Ambiente (PRODEMA) na Universidade Estadual de Santa Cruz (UESC) - Ilhéus / Bahia - Brasil. E-mail: ccprofice@uesc.br ORCID: 0000-0002-1972-9622 Lattes: http://lattes.cnpq.br/2410356941075360

${ }^{4}$ Mestre em Educação pela Universidade Federal do Estado do Rio de Janeiro (UNiRIO) - Brasil. Pesquisador no campo das ciências sociais em interface com o campo do Direito E-mail: migtiriba@gmail.com ORCID: 0000-00019828-3501 Lattes: http://lattes.cnpq.br/8605203940803020 


\section{Introdução}

A escrita deste artigo se deu entre março e maio de 2020, quando da ameaça do Covid-19, um dos coronavírus que vêm, sucessivamente, ameaçando a humanidade. Dirigimos nosso olhar para as relações dos seres humanos com a natureza, e, a partir daí, para nossos povos originários, que, ainda nos dias de hoje, 500 anos após a invasão do colonizador, perseveram em visões de mundo/modos de vida em clara oposição às formas de organização social ocidental dominante.

Trazemos os povos originários ao centro da cena, primeiramente, pela necessidade de afirmação de seu direito à existência. Pois, apesar do forte movimento de resistência, hoje, mais que nunca, estão ameaçados pela retirada de direitos conquistados, pela invasão permanente de seus territórios, pela queima da floresta, pelo arruinamento das águas e das terras, pela fome, agora por um vírus poderoso. Mas a aproximação se dá também pela necessidade de estabelecermos contrapontos à civilização ocidental que, em seu processo de degeneração, abre espaços para o surgimento de epidemias e as pandemias devidas à ação devastadora do capitalismo.

Neste sombrio momento buscamos filosofias e modos de vida afirmadoras do pertencimento ao cosmos, em contraposição a concepções e práticas que agridem os ambientes naturais por atribuírem ao ser humano uma posição de centralidade em relação ao universo.

Ainda que sejam muitas as diferenças entre seus modos de vida, embora habitem diferenciados meios sociogeográficos, mantenham estilos de vida e modos próprios de expressão, os povos indígenas brasileiros têm suas vidas organizadas em sintonia com os ciclos da natureza (CRUZ, 2012). Assim, seus saberes e afetos estão associados à relação com o cosmo, à ancestralidade, aos modos de vida e manejos dos recursos naturais em equilíbrio dinâmico com o ecossistema. O território guarda a memória e materializa o sentimento de pertencimento, é fonte de reprodução e de recursos materiais e assegura a sobrevivência material. Outra marca das culturas originarias diz respeito às formas de organização econômico-produtiva, em que o sentido do trabalho é o de suprir as necessidades do coletivo, não do indivíduo. Tampouco há a intenção de acúmulo ou produção de excedente em grande escala, além das trocas locais. As energias produtivas são destinadas à subsistência do grupo e à manutenção das práticas sociais, festas e rituais, e não ao mercado capitalista. As 
relações de poder são horizontais. Não há lugares de chefia; são as lideranças instituídas por sua idade e sabedoria, ou ainda por linhagens familiares, que orientam política e espiritualmente, em direção à cooperação. Tomando de empréstimo as palavras de Maturana e Varela (1995, p. 23), podemos dizer que nossos povos originários se constituem subjetivamente, no sentido da afirmação de "impulsos altruístas, presentes desde o começo de nossa vida de seres sociais (...) condição biológica de possibilidade do fenômeno social: sem altruísmo não há fenômeno social".

Consideramos que o "sistema mundial capitalista-urbano-industrial-patriarcal" (GUATTARI e ROLNIK, 1986, p. 15-16) inclui todos os modelos econômicos que fizeram/fazem da natureza simples objeto de dominação, exploração, consumo e descarte. Consideramos também que o socialismo, como fruto da Revolução Industrial, também se relacionou/relaciona com a natureza tomando-a como matéria prima para a produção de bens. Assim, apesar de propor a propriedade coletiva dos recursos naturais e a distribuição igualitária do que é socialmente produzido, do ponto de vista das relações com a natureza, as formas de organização das sociedades socialistas não consideraram que a sua preservação está para além da luta contra a apropriação privada dos recursos naturais e dos bens que eles geram. Pois não bastam mecanismos de controle público e justa distribuição da riqueza, é necessário produzir de forma sustentável.

A necessidade de ruptura com o que está hegemonicamente instituído distância as nossas pesquisas de padrões eurocêntricos. Na contramão de antropocentrismos, individualismos, racionalismos, racismos e patriarcalismos (que, enredados, estão na origem da crise generalizada das condições de vida no planeta), realizamos um mergulho nas filosofias de povos originários e tradicionais brasileiros. Dirigimo-nos, em especial, às crianças, pela necessidade de conhecer modos de pensar, de sentir e de educar pautados por pressupostos altruístas. Atuando junto a educadoras de crianças urbanas, e por meio de nossas próprias experiências em educação, identificamos conexões entre o modelo de desenvolvimento econômico e práticas escolares que desconsideram os apelos infantis de convívio com o ambiente natural. Consideramos que as formas de organização dos espaços/rotinas escolares, ao distanciar as crianças da natureza, produzem sentimentos de desconexão física e emocional, necessários a uma visão do ambiente como objeto de conhecimento, 
domínio e controle, em consonância com os interesses do sistema capitalista. Para designar esta condição de distanciamento, utilizamos a expressão "emparedamento", em alusão ao diminuto tempo em espaços abertos e ao longo tempo em que as crianças permanecem em espaços fechados: oito, nove ou mais horas diárias (TIRIBA, 2005). Mas o conceito de emparedamento denuncia também sofrimentos que são decorrentes do sofrimento imposto pela vida em espaços entre-paredes, abrangendo as travas corporais, a ênfase no desenvolvimento racional, o controle do devaneio, a sufocação estética, o impedimento de contato físico e espiritual com o que afeta (SPINOZA, 2009). Enfim o conceito de emparedamento denuncia um modo moderno de organizar a vida que interfere maleficamente no desenvolvimento pleno do humano.

O modelo escolar dominante - via contenção de corpos e controle de desejos reproduz os pressupostos do paradigma moderno, ao separar as crianças natureza, eleger a razão como caminho exclusivo de conhecimento e definir os humanos como seres de racionalidade, deixando de fora outras dimensões importantes da existência. Em linha inversa, nos processos de educação das crianças indígenas, a liberdade e a autonomia são determinantes. Para dar conta do universo de questões que nos desafiam neste momento de comoção e medo, organizamos esse artigo em três partes, relativas: (a) às relações entre seres humanos e natureza em um contexto de pandemia; (b) às condições de existência dos povos originários, vítimas mais frágeis do COVID-19; e (c) à importância de aprendermos com esses povos e com suas crianças os saberes necessários a modos de organização social em equilíbrio com a biodiversidade.

Na primeira parte, trazemos informações e reflexões sobre relações entre seres humanos e natureza sob a ótica da ecologia política. Abordamos a emergência ambiental planetária, em suas dimensões biofísicas, sociais e econômicas, ainda mais evidenciada com a entrada em cena do COVID. O novo coronavírus põe em risco e altera radicalmente a existência humana sobre a Terra, mas também faz tremer o ideário antropocêntrico da modernidade, que omite a unidade da vida, a hierarquiza e, por subjugo e sobre-exploração, a ameaça. Na segunda parte, lançamos um olhar para os povos originários brasileiros, com o objetivo de compor um retrato de suas condições atuais de existência, impactadas por mega projetos neoliberais, em um contexto de desrespeito/violação de direitos, agora potencializado pelo estado de 
pandemia. Na terceira e última parte, o olhar se volta mais diretamente para as infâncias indígenas, abordando concepções de criança, relações com a natureza e o seu lugar na organização das sociedades originárias. Nesta perspectiva, o texto aproxima visões de mundo não hegemônicas, ao promover diálogos entre a filosofia de Spinoza e saberes de povos indígenas brasileiros. A intenção é trazer a realidade cotidiana das crianças indígenas e contrastá-las com a realidade das crianças urbanas, com vistas a afirmar os modos de educar comprometidos com a saúde das crianças e do planeta.

\section{Relações entre seres humanos e natureza}

A ecologia política, social ou, simplesmente, ecologia dos pobres, aborda a questão do meio-ambiente e da natureza voltada para as desigualdades e os conflitos socioambientais e orientada pela ideia de justiça ambiental (MUNIZ, 2009; PEREIRA; DIEGUES, 2010). Como define Muniz (p. 184), a ecologia política se caracteriza por ser um "movimento" simultaneamente político e acadêmico (...) e que trouxe para a discussão acadêmica e intelectual a "crise ambiental", como resultante do colapso entre crescimento econômico e a base finita dos recursos naturais". Contudo, para a ecologia crítica de Latour (2004), trata-se de abandonar definitivamente a ideia da natureza como algo exterior, ou mesmo superada, pela nossa condição social. A natureza nos é interior, nós somos a natureza. As relações entre natureza e pessoas e sociedades e culturas são, como destaca Harvey (2020), metabólicas, porque compartilhamos fluxos de matéria e energia com outros modos e expressão da natureza - humanos e não humanos, somos mutuamente afetados em nossos processos auto regulatórios e homeostáticos.

El capital modifica las condiciones medioambientales de su propia reproducción, pero lo hace en un contexto de consecuencias involuntarias (como el cambio climático) y con el trasfondo de fuerzas evolutivas autónomas e independientes que andan perpetuamente reconfigurando las condiciones ambientales. (p.82).

Neste sentido, a ecologia política de Latour (2004) pensa para além da ontologia e propõe a retomada da desigualdade e distinção inaugural que se estabeleceu entre pessoas e natureza na racionalidade ocidental. Conforme o autor, desde a caverna de Platão, a natureza ficou do lado de fora, verdadeira, mas externa 
à ilusão sombreada e enganosa de seu interior, ocupada apenas por homens de visão limitada às sombras projetadas por uma luz que não conheciam. Poucos foram os humanos que saíam da penumbra para constatar a existência de uma verdade palpável e mensurável, não camuflada pelas sombras, mas plena em sua realidade. Estes sábios retornavam para contar aos quase cegos o que havia lá fora; não para chamá-los para fora, mas para consolidar esta separação de mundos e de possibilidade de trânsito entre eles.

Seguindo em sua crítica da alegoria platônica, Latour (2004) argumenta que a cegueira dos humanos ocidentais dentro das cavernas tem ramificações na ecologia, é esta última que não reconhece no mundo social a mesma legitimidade do mundo e dos seres da verdadeira natureza. Essa pendência biocêntrica da ecologia clássica, reverso natural da moeda antropocêntrica da filosofia ocidental, também se orienta por um desprezo descrente do mundo social que seria necessariamente deletério à natureza, em menor ou maior escala. A ecologia biológica permanece encantada com a natureza que lhe é exterior, mesmo dentro das cavernas, revelando que no seu interior e em suas bordas existem ecossistemas com seres e substâncias, líquidos percolando, insetos da escuridão, rochas amontoadas, morcegos que entram e saem. Pelo lado das ciências humanas, serão a antropologia cultural e a arqueologia que, ao contrário de descrever a caverna como locus da ignorância, a revelam como nosso primeiro refúgio e abrigo, onde o fogo podia ser mantido aceso, as feras afastadas e as entradas e saídas controladas. Nas paredes das cavernas, encontramos suporte pra arte. De seus contornos e reentrâncias, fizemos uso. Em seus recônditos os mortos foram sepultados e, desse modo, protegidos. Arte, expressão, cultos sagrados (LEROI-GOURHAN, 1971), a caverna é nossa natureza humana também.

A Ciência se configura como "única salvação para o inferno social". (2004, p. 31). Aqui, Latour conclui que a ruptura humanidade-natureza se consolidou, permanece e se pretende hegemônica porque ela é política, ela trata da divisão dos territórios, das coisas e dos seres transformados por nós em recursos. Então a natureza é palco político de competições e colaborações, de perseverança ou de destruição. Para Latour, "concepções de política e concepções de natureza sempre formaram uma dupla tão rigidamente unificada como os dois lados de uma mesma gangorra, em que um se abaixa quando o outro se eleva e inversamente" (2004, p.59). 
Propomos aqui uma aproximação entre a ecologia política crítica, que convoca para a suspensão conceitual do a priori dicotômico humano-natureza, e a filosofia da natureza, ou substância espinosana, que se expressa por seus atributos: extensão e pensamento. Nós, humanos, também somos expressão desta natureza, fonte e imanência de tudo. Somos corpos da Natureza entre tantos outros: gente, bicho, planta, lua, sol, casa, barco, tudo é de lá, tudo vem de lá (DELEUZE, 2002). Em Espinosa, os seres, nós inclusive, somos todos modos de expressão de uma mesma e imanente Natureza, e que se definem por seu poder de afetar e ser afetado, graus de potência que diminuem ou aumentam a nossa capacidade de agir. É esta a ética ou, em termos atuais, a bioética espinosana.

Pela via da ecologia política e do pensamento espinosano, nos aproximamos da biofilia. Segundo o criador do conceito, Edward Wilson (1984), a biofilia é uma tendência inata a focar na natureza e nos seres vivos. Já Fromm (1973) entende a biofilia em seu aspecto psicossocial, opondo-se à necrofilia e à impulsos destrutivos, pessoais e coletivos. Conforme sua própria definição, "A biofilia é o amor passional pela vida e por tudo que é vivo; é a vontade de crescer, seja em uma planta, uma pessoa ou um grupo social" (FROMM, 1973, p. 365). Defendemos que - por nossa condição biofílica, querendo ou não, tendo consciência ou não - somos natureza, modos de expressão da mesma substância que é tudo o que se conhece e tudo que pode ser, independente de nosso conhecimento. Conhecimento só alcançável por meio de nossos corpos, em sua dinâmica. Buscando integrar a ecologia política com a biofilia, ao invés de nos paralisarmos no dilema da culturalidade ou naturalidade dos humanos, optamos por explorar a sociobiodiversidade (DIEGUES, 2001) como expressão da complexidade ambiental que coloca em interação humanos e nãohumanos, seres animados e inanimados, processos biofísicos e metabólicos.

No território que hoje chamamos Brasil, as comunidades originárias vivenciam a chegada dos povos europeus com suas próprias e muito diferentes concepções de natureza, hoje ameaçadas não mais pela investida colonial, mas por projetos da ordem neoliberal. O processo de formação como território nacional se apoiou na exploração, corporal e cultural, do indígena e a consequente invasão biológica de seres humanos, vírus e animais domésticos (PROFICE; SANTOS, 2017). Nas colônias, com a adoção de um modo de vida agrícola, sedentário e, posteriormente, urbano, nos moldes do pensamento europeu ocidental, o apartamento entre humanos 
e natureza se forjou e consolidou. Este avanço colonizador sobre a natureza tropical foi a base sobre a qual se deu a consolidação do capitalismo neoliberal e seus megaempreendimentos na floresta, como veremos na seção seguinte.

\section{A condição indígena}

Aqui fazemos uma breve retrospectiva da luta incessante dos povos originários, ao longo de cinco séculos, pelo direito à soberania, isto é, pelo direito à decidir autonomamente sobre os modos de organizar sua vida social. Desde a invasão, em 1500, vêm sendo expulsos e encurralados em função dos ciclos econômicos do ouro, da cana, do café, da borracha, etc. Agora, ainda mais acentuadamente, pela derrubada da floresta, pela soja, pelo boi.

Até meados dos anos 70, acreditava-se na inexorável extinção da população indígena. Entretanto, os anos 80 apontaram uma tendência de reversão da curva demográfica. Segundo dados do Instituto Brasileiro de Geografia e Estatística (IBGE, 2010), existem aproximadamente 305 etnias totalizando 896,9 mil indígenas distribuídos pelo território brasileiro ${ }^{5}$.

A disputa por territórios, o acesso, o uso e a apropriação da terra remetem à colonização portuguesa, através da concessão de sesmarias; depois, ao latifúndio e à grilagem, viabilizada por falsificação, em larga escala, de documentação de posse de terra. O resultado dessa política foi o extermínio de milhões de indígenas, dada a destruição de suas relações com o território.

A partir das primeiras décadas do século passado, a demarcação de reservas para usufruto de indígenas teve o objetivo de confinar os grupos, indígenas, liberando, assim, o restante do território para a colonização (BRANDT, 2001; REZENDE, 2011). Constituíram-se, portanto, como "estratégia governamental de colonização e consequente submissão da população indígena aos projetos de ocupação e exploração dos recursos naturais por frentes não indígenas" (BRANDT, 2011, p.16).

\footnotetext{
${ }^{5}$ Registra-se atualmente dentre os territórios indígenas isolados, 54 terras isoladas e 24 unidades de conservação. https://pib.socioambiental.org/pt/\%C3\%8Dndios_isolados, acessado em 29/05/2020. De acordo com dados do IBGE (2010), 36\% dos povos indígenas vivem em áreas urbanas. Entre $2000 \mathrm{e}$ 2010 houve uma queda dessa população de 58.464 pessoas nos centros urbanos, indicando que os índios estão voltando as suas terras de origem (https://www.socioambiental.org/pt-br/blog/blog-domonitoramento/ibge-detalha-dados-sobre-povos-indigenas, acessado em 29/05/2020)
} 
De acordo com o Relatório da Comissão Nacional da Verdade (2014), os povos indígenas sofreram graves violações de direitos humanos entre 1946 e $1988 .{ }^{6} \mathrm{Em}$ um primeiro período, a violação se caracterizou majoritariamente (mas não exclusivamente) pela omissão da União, acobertando o poder local e interesses privados, propiciando a extração de madeira e minérios, a colonização e obras de infraestrutura em terras indígenas. Em contradição, o posicionamento dos irmãos Villas-Bôas acerca da política indigenista brasileira, tributário das ideias do Marechal Rondon, abriu espaços para políticas protecionistas e preservacionistas. Como resultado, em 1961, foi criado o Parque Nacional do Xingu, a mais importante reserva indígena das Américas, com vistas a resguardar as culturas originárias, assim como a preservar a fauna e a flora ainda intocadas da região. Já no segundo período, é nítido o protagonismo da União no aviltamento de direitos humanos, notadamente na área de saúde e no controle da corrupção. A promulgação do Ato Institucional no 5 (Al-5), em 1968 cedeu terreno às atividades associadas à extração de madeira e minérios, à colonização e a obras de infraestrutura. Foi a partir da ditadura militar que o governo federal passou a tomar medidas a fim de tornar efetiva a ocupação na Amazônia ${ }^{7}$.

Os movimentos de resistência à Ditadura Militar possibilitaram maior visibilidade ao drama indígena, ganhando ainda mais impulso no período da redemocratização política do Brasil, pós-1980 (KEHL, 2014). Grande parte das conquistas estão concentradas no Capítulo VII, artigos 231 e 232 da Constituição Brasileira (BRASIL, 1988): o reconhecimento dos modos de vida, no que concerne às formas de organização, costumes, línguas, crenças e tradição.

\footnotetext{
${ }^{6}$ https://edisciplinas.usp.br/pluginfile.php/4469887/mod_resource/content/1/Volume\%202\%20\%20Texto\%205\%20-\%20Povos\%20Indi\%CC\%81 genas\%20na\%20CNV.pdf, acessado em 25/03/2020 ${ }^{7}$ Em 1968 foi lançada a Operação Amazônia e criado o Instituto Nacional de Colonização e Reforma Agrária (INCRA), além da Superintendência de Desenvolvimento da Amazônia (SUDAM). Como "solução" para o conflito de terras, o governo deu início à expansão da fronteira agrícola. O objetivo era financiar a construção de infraestrutura nas áreas de atuação da SUDAM, promovendo a integração da Amazônia à estrutura espacial nacional, mediante ocupação às margens da rodovia Transamazônica. Além desta, foram construídas as rodovias Cuiabá-Santarém (BR-163), Manaus-Porto Velho (BR-364) e Perimetral-Norte (BR-210). A abertura da BR-230 nos anos 1970 modificou drasticamente o sudeste do Pará. A castanha extrativista, predominante até então, deu lugar à criação de gado, prejudicando assim a qualidade de vida. Ademais, os povos Parakanã foram afetados pela construção da Estrada de Ferro Tocantins, da usina hidrelétrica de Tucuruí e pela abertura da Transamazônica. Em 1971 o primeiro grupo foi contatado e sofreu um decréscimo populacional de $54 \%$ em uma população de cerca de 200 índios, consequência das doenças transmitidas por trabalhadores da estrada e por funcionários da Funai. O mesmo ocorreu com os Asurini do Xingu.
} 
Entretanto, apesar dos movimentos em defesa da soberania, e de estarem assegurados legalmente os direitos sobre as terras originariamente ocupadas, 0 avanço das práticas capitalistas vem intensificando ainda mais as formas de expropriação e rompimento com a principal forma de reprodução de vida (a terra), entre indígenas, lavradores e quilombolas. São inúmeras as ameaças, sobretudo decorrentes da pressão exercida pela bancada ruralista do Congresso Nacional brasileiro, que envolvem a exploração e expulsão das populações originais e tradicionais, por meio de ações predatórias do capital, dadas pelos grandes empreendimentos, tais como hidrelétricas, barragens, exploração de minérios, entre outras.

Nos anos mais recentes a construção da Usina Hidrelétrica de Belo Monte na bacia do Rio Xingu, norte do estado do Pará, resultou em um processo de desconstituição étnico-cultural de povos como os Juruna, Parakanã, Arara e Munduruku. Consoante o Dossiê Belo Monte, elaborado pelo Instituto Socioambiental/ISA, a construção dessa usina pela empresa Norte Energia em parceria com a prefeitura de Altamira, gerou e ainda gera inúmeras violências contra os povos originários na Região Amazônica. Entre elas, a perda da própria língua, que se encontra em desuso entre parte das crianças e jovens munduruku ${ }^{8}$.

Embora seja ainda hegemônica uma visão dos indígenas como membros de sociedades sem regras e sem estrutura social, ganha força a concepção de que suas sociedades são estáveis, equilibradas, sustentadas na convivência em princípios éticos que asseguram relação orgânica, política, social, vital com a terra. Caminhando na contramão do etnocentrismo, em "A sociedade contra o Estado", Pierre Clastres (1974), nega a ideia de evolução das sociedades em função de ausência ou presença do Estado. Para Clastres não existe sociedade superior nem inferior. $O$ autor critica o argumento de que as comunidades indígenas possuem uma economia rudimentar, haja vista que as forças consideradas primitivas se unem para oferecer o mínimo necessário para atender às necessidades de seus povos. Clastres desconstrói a ideia da sociedade do ócio, a partir da consideração de que são necessárias poucas horas de dedicação à colheita, em padrões suficientes para saciar as necessidades da população indígena. Trazendo as colocações do autor para a realidade brasileira, podemos considerar que a autossuficiência é um dos elementos possibilitadores da

\footnotetext{
${ }^{8}$ https://pib.socioambiental.org/pt/Povo:Munduruku, acessado em 25/05/2020.
} 
vida de cerca de 69 povos indígenas isolados no território nacional ${ }^{9}$. O outro elemento é a necessidade de manter distância de tudo que ao longo da história só trouxe a morte.

Para Clastres (1974), o Estado é possível, mas não necessário. Os povos sem Estado, como os indígenas brasileiros, não são involuídos socialmente que em algum momento de seu desenvolvimento histórico dariam lugar a Impérios, Monarquias e Estados. Não se organizar em Estados, mas em Comunidades, é uma possibilidade social. Vamos entender aqui Comunidades como agrupamentos humanos que podem se articular com outros, onde seus membros vivem sem diferenças econômicas e hierarquia social rígida ou intransponível; a economia não está regulada pela da produção em quantidade, nem o objetivo do trabalho, ou da exploração dele, visa o acúmulo ou lucro.

Ontem, como hoje, a migração frequente e a vida em terras exíguas interferem negativamente em modos de ser, pensar e viver indígenas. Toda a tradição é posta em suspenso sempre que são alteradas a sua organização social, a relação com o território, os modos de exploração dos recursos naturais aí existentes. À medida que são retiradas as condições materiais para a atividade de caça e pesca, atribuídas aos homens, como para as atividades de cuidado da terra, atribuídas as mulheres; a dificuldade de produção de alimentos altera profundamente a sustentabilidade de seus modos de vida e os faz dependentes de políticas governamentais assistencialistas, como a de distribuição de cestas básicas.

Distantes da terra, as mulheres indígenas perdem prestígio social em função da impossibilidade de permanecerem como produtoras de alimentos, o que as isola, as confina e as coloca em situação de dependência. A precarização de condições socioeconômicas abala o seu prestígio de detentoras de conhecimentos relativos às práticas tradicionais, hábitos alimentares e regras sociais, o que desfavorece as mulheres, ou até mesmo as impede de desempenhar suas funções sociais/maternas.

\footnotetext{
${ }^{9}$ Povos isolados são grupos indígenas com ausência de relações permanentes com as sociedades nacionais, seja com não índios, seja com outros povos indígenas. Esse isolamento pode ser atribuído ao insucesso dos encontros com as demais sociedades, caracterizado pela infestação de doenças, infecções, epidemias, atos de violência física, espoliação dos recursos naturais e até morte. Ademais 0 isolamento associa-se à experiência de uma sociedade autossuficiente economicamente e social. https://pib.socioambiental.org/pt/\%C3\%8Dndios_isolados, acessado em 29/05/2020.
} 
Como as crianças internalizam as relações sociais (VIGOTSKI, 1989) não se pode imaginar seu bem estar desvinculado do bem estar de suas mães.

Com a acentuação do processo de desmatamento, as comunidades indígenas são destruídas, os moradores, dispersos e as famílias, desarticuladas. Tornam-se precárias as condições de manutenção de práticas religiosas, especialmente os rituais de iniciação de meninas e meninos, alterando-se, assim, a tradição de educá-las/los segundo papéis que são próprios de cada grupo étnico atingido. A exposição à sociedade de consumo, sem condições para consumir, abre espaços para a baixa autoestima. As tensões não apenas criam ambiente para o mal estar e para práticas de violência, suicídio e alcoolismo, como também para o desmembramento de grupos e mudanças para as beiras de estrada e periferias urbanas (URQUIZA; NASCIMENTO; VIEIRA,2011). É nesse ambiente hostil que as crianças - deslocadas de suas terras e arrancadas de suas tradições por mega empresários, grileiros, autoridades públicas, com o apoio ou a condescendência dos governos - são jogadas em meios sociais para quem seu povo é indesejável, selvagem, primitivo e imprestável.

\section{Diálogos entre saberes contra-hegemônicos}

Nossa intenção, aqui, é dar visibilidade a modos de viver, sentir e pensar, cujas raízes culturais são incompatíveis com o sistema-mundo moderno-colonial (PORTOGONÇALVES, 2017). Lançamos um olhar para as crianças pertencentes a grupos humanos cuja ecologia política se funda em relações harmônicas entre as práticas sociais e o ecossistema em que estão inseridos. Estas relações são asseguradas, nos planos material e subjetivo, por dimensões intrínsecas e indissociáveis à constituição humana. De modo genérico, é possível afirmar que essa liga está na base das culturas indígenas brasileiras. Ela se afirma, geração após geração, via processos educativos coerentes com uma visão de mundo que afirma a unidade do humano com o cosmos.

É preciso lembrar que a criança não é uma categoria natural. Os conceitos de criança e de infância de cada sociedade/grupo social emergem de condições sóciohistóricas, culturais e ambientais em que vivem: crescer em uma aldeia indígena amazônica é diferente de crescer na caatinga nordestina, em uma favela carioca ou em um bairro de classe média de São Paulo. O que hoje está em disputa é a afirmação 
de uma visão de criança como frágil e incapaz, que requer políticas de controle e submissão. Interessa que sejam sentidas e compreendidas como "Uma presença através de uma ausência" (PANCERA, 1994, p.103), em oposição ao adulto que ainda não é. Entretanto, se ontem a entendíamos em oposição aos adultos, hoje podemos olhá-las como pessoas concretas, de carne, osso e afetos; habitantes de um território, detentoras da memória de sua existência, constituídas no compartilhamento com os adultos em lutas pela sobrevivência, lutas de resistência, pela comida, pela moradia (CARREIRO; TAVARES; 2018; ARROYO; VIELLA; SILVA, 2015).

Como os povos indígenas concebem as crianças? Embora a cada etnia corresponda um modo próprio de conceber a vida, é possível afirmar que, de modo geral, como uma etapa da vida cujas particularidades devem ser valorizadas e respeitadas (BRANDT, 2011; LANDA, 2001; BERGAMASCHI, 2011; GOMES; SILVA; DINIZ, 2011).

Com vistas a evidenciar dimensões, comportamentos e atitudes humanas pouco valorizadas no ocidente, fazemos uma aproximação entre visões de mundo que não se afirmaram como hegemônicas. Essa opção se dá pela sintonia entre concepções de Baruch Spinoza (1642-1677) e a de povos originários brasileiros. Spinoza, expoente da cultura europeia em resistência contra os valores do capitalismo emergente, foi excomungado pela tradição religiosa judaico-cristã (DELEUZE, 2002); tal como as "bruxas" foram perseguidas e queimadas por defenderem os territórios, os modos de organização econômica e política que o capitalismo emergente engendrou (FEDERICI, 2019; MIES; SHIVA, 1997).

Próxima a visões indígenas que afirmam a unidade da vida, na perspectiva espinosana, a existência humana se dá em estado de conexão com o universo. Tudo está em rede, Corpo e alma são expressões indissociáveis, são atributos do ser que se manifestam como extensão e/ou como pensamento (SPINOZA, 2009, Ética IV). Na visão do filósofo, os seres são modos de expressão da natureza que se manifestam em diferentes graus de potência, não há uma hierarquia entre eles. O antropocentrismo não faz sentido porque, como efeito da condição de entrelaçamento, os seres se interconectam e se fortalecem na medida da força dos afetos que asseguram o estado de conexão. Não há hierarquia. As diferenças entre espécies se dão em parâmetros relativos ao grau de potência de afetar e ser afetado (SPINOZA, 2009, Ética III). Assim, os humanos não ocupam uma posição de centralidade em 
relação a todo o universo. Na mesma direção, as doenças ou a morte são provocadas por atitudes predatórias de entidades cósmicas contra os humanos. Nas palavras de Tassinari (2007).

Entre mortos e vivos, entre deuses, animais e humanos, há uma relação agonística constante marcada pela possibilidade da captura das crianças do outro. Tudo se passa como se cada categoria cósmica buscasse, através das crianças, fazer valer seu "ponto de vista" (p.19).

A liberdade de brincar livre e autonomamente, de circular por espaços da aldeia a que só elas têm acesso são marcas importantes da constituição indígena. O brincar é uma atividade universal entre os humanos. Para Vygotsky (1989), o brincar é uma atividade constitutiva de nossa humanidade: as crianças brincam porque brincar é uma fonte do seu desenvolvimento, é um caminho de acesso à realidade, à cultura. E, simultaneamente, o brincar possibilita uma leitura singular desta mesma cultura, desenhada através de sistemas simbólicos próprios, através dos quais a criança recria a realidade. Brincar é, portanto, uma atividade cultural, além de ser uma atividade psicológica.

A partir da filosofia de Spinoza (2009), podemos acrescentar que as crianças brincam pela necessidade de se manterem como parte de um universo único. Como membros de uma espécie que existe em conexão com milhares de outras espécies, os infantes humanos, brincando, mantém viva esta conexão. Brincam porque afetam e são afetadas por outras espécies, seres e processos naturais que compõem também a natureza-ambiente de que são parte. A sua integridade depende do estado de conexão porque a potência da vida está relacionada à diversidade, à existência de muitas formas de vida que conversam entre si: trocam oxigênio, água, calor, afeto, tudo de que necessitam para manter o equilíbrio de cada indivíduo e do meio que habitam. Quanto maior forem as trocas, quanto maior a diversidade de espécies, maiores as possibilidades da vida se manter, perseverar (MATURANA, 1998).

Os infantes humanos são membros de uma das espécies que participam da dança da vida. Movimentam-se em relação a outras formas de vida, desejam isso, pedem isso no dia a dia da vida e da escola porque necessitam manter-se em conexão. É essa possibilidade que o movimento brincante propicia, como fruto e expressão da potência de agir, que assegura aos sujeitos o fortalecimento do conatus. Esse conceito define o esforço de perseverar na vida, enquanto modos de expressão da natureza que existem são entrelaçados com outros modos de expressão não 
humanos, por quem se sentem atraídas, e com quem as crianças sempre desejam brincar.

Como vimos na primeira parte, os humanos têm uma atração inata, uma tendência a associar-se a outras formas de vida, condição para um processo de evolução que sempre se deu em co-evolução com os demais seres e sistemas vivos (WILSON, 1984; PROFICE, 2016, 2018). Segundo os autores, essa atração, que denominam como biofilia, depende de modos de viver e de educar: uma cultura que alimenta a proximidade gera sentimentos de afeição e, consequentemente, praticas de proteção à natureza; uma cultura que alimenta o distanciamento produz sentimentos e atitudes de desapego, indiferença e, até mesmo, práticas de agressão. O conceito de biofilia revela e evidencia relações entre as condições ambientais do planeta e sentimentos e comportamentos humanos, socialmente construídos. Ele nos leva a pensar que a educação das crianças indígenas alimenta sentimentos de pertencimento ao ambiente; que este sentimento se traduz no desejo e no compromisso com a sua preservação, o que certamente contribui para que uma grande parte das áreas protegidas do Brasil estejam situadas em terras indígenas ${ }^{10}$.

A potência de agir ganha força quando o desejo impulsiona aos bons encontros.A via do desejo permite uma aproximação com conceitos espinosanos. Para o filósofo, o desejo é a inclinação por algo que julgamos útil para nossa conservação. Assim, o desejo não é falta; pelo contrário, é potência que orienta a vida afetiva, sempre no sentido de fortalecer o conatus, pois "[...] nenhuma coisa tem em si algo por meio do qual possa ser destruída, ou retirada a sua existência. E esforçase assim, tanto quanto pode e está em si, por perseverar em seu ser" (SPINOZA, 2009, p. 105).

Em sentido oposto, a negação do desejo enfraquece o conatus, conduz ao aprendizado da alienação, em relação a si mesmas e ao mundo, portanto, à despotencialização, ao entristecimento. Ao contrário, a potência, a alegria e a liberdade são decorrentes do aprendizado da consciência de si e do mundo,

\footnotetext{
${ }^{10}$ De acordo com o Instituto Socio ambiental/ISA, as Terras Indígenas na Amazônia abrigam 173 etnias indígenas e são fundamentais para a conservação da biodiversidade regional e global, pois as comunidades indígenas reconhecem o valor da floresta em pé na proteção e manejo dessas áreas. Enquanto $20 \%$ da floresta amazônica brasileira foi desmatada nos últimos 40 anos, as Terras Indígenas na Amazônia Legal perderam, somadas, apenas $2 \%$ de suas florestas originais. https://www.socioambiental.org/pt-br/blog/blog-do-monitoramento/a-demarcacao-das-terrasindigenas-e-decisiva-para-conter-o-desmatamento-e-manter-funcoes-climaticas-essenciais. $22 / 06 / 20$

Acesso
} 
possibilitada pela conexão com aquilo que verdadeiramente mobiliza o ser (DAMÁSIO, 2004; GLEIZER, 2005).

Como exemplo de aprendizado da consciência de si, trazemos o estudo antropológico de Elizabeth Pissolato (2007), que investiga a busca de alegria, de bemestar, em duas aldeias Guarani Mbya do litoral do estado do Rio de Janeiro. De acordo com a autora, deslocar-se frequentemente, de um território a outro, é um modo de vida, é um modo de ser. Perguntados sobre o porquê do deslocamento (que, nas condições atuais, são realizados em pequenos grupos, ou por indivíduos, homens e mulheres, e mesmo jovens e adolescentes), os guarani mbya respondem que se deslocam para buscar, em outros territórios, geralmente ocupados por sua etnia, o que acreditam que os fará mais alegres do que se encontram no lugar onde estão. Referindo-se à filosofia espinosana, Deleuze (2002, p.34) afirma a alegria como um afeto que assegura o fortalecimento e a potencialização do humano: “(...) somente a alegria é válida, só a alegria permanece e nos aproxima da ação e da beatitude da ação. A paixão triste é sempre impotência". Assim, a decisão de deslocar-se exige uma autonomia que é fruto de conexão profunda com os sentimentos; uma inteireza que se só constitui em condições de liberdade, sem a qual é impossível sentir-pensaragir a partir de causas próprias (SPINOZA, 2009)

Em culturas originárias, o princípio da autonomia se relaciona ao exercício de enxergar-se e manter-se ativo no mundo; diz respeito à criação de condições para tornar-se capaz de tomar suas próprias decisões, a partir de suas próprias necessidades, de seu bem estar e do outro (TASSINARI, 2007; NASCIMENTO; URQUIZA; VIEIRA, 2011; SILVA; NUNES; MACEDO, 2002).

Como em Spinoza, a submissão a forças alheias fere a essência do ser, o colocam à deriva, por isso entristecem. As condições de desigualdade interferem negativamente na essência entendida como natureza existente, imanente, pois a consciência do que se sente é, a cada momento, guiará em relação aos encontros que faz; em sintonia fina com o desejo, orientará na escolha de afetos que potencializem, que assegurem a alegria. As vivências não são definidas por adultos, não obedecem à definição prévia de objetivos e/ou habilidades a serem alcançadas, mas sim estão coladas no desejo e respondem aos chamados da natureza, das crianças e de_seus corpos (TIRIBA, 2010; TIRIBA; PROFICE, 2012; 2019). Esse modo de constituição humana corresponde a uma ecologia política definida por relações de 
proximidade com a sociobiodiversidade. Ao contrário, o sentimento de opressão despotencializa, entristece.

Desejo, potência, alegria, liberdade, autonomia: esses são elementos básicos da educação indígena, a serem incorporados aos processos de educação de todas as crianças brasileiras.

\section{Considerações finais}

Apesar da política de extermínio levada à frente durante séculos, com raros e curtos períodos, nossos povos originários estão presentes. A fisionomia da população, a literatura, os banhos de todos os dias, o nosso linguajar, os nomes de ruas, cidades e vilarejos: a cultura brasileira expressa a presença histórica de nossos ancestrais.

Latour (2004) nos convoca a sair da caverna. Sem esse deslocamento, nada será possível. O ambiente social não é necessariamente corrompido, não é uma sombra tremulante e imperfeita do real - este último sempre justo, destituído de opiniões, legitimado em sua ontologia que nos é independente, se expressa por meio de objetos limpos e sem risco -. Aí se localiza, conforme a ecologia política, a fenda radical entre humanidade e natureza que se estende fincada em toda racionalidade ocidental, que se infiltra e mina, como filosofia, entre as pedras porosas da caverna e forma um lago de fundo infinito que chamamos Ciência. A ciência, conforme Latour, só é possível a partir desta ruptura, na qual o sábio, e mais tarde o cientista, tem acesso ao lado de fora da caverna, o mundo objetivo, e depois pode entrar na caverna e contar aos que ali ficaram aprisionados como ele se configura. De fato a natureza não está em crise e sim a objetividade. A partir daí, acreditamos, é que os povos indígenas têm a nos ensinar sobre Natureza, sendo parte dela. Então todo estudo é, ao mesmo, tempo autorreflexão. A cultura fala da planta, fala do animal, fala do céu, fala de mim e de meu povo. Todas essas são suas expressões e intensidades. A cultura canta, dança, reverência seres que vemos e que não vemos, mas estamos todos no mesmo plano de imanência, ainda que em diferentes dimensões. Os seres e processos vivos da natureza, no nível molar e molecular, com substâncias in natura ou beneficiadas, nós somos isso também e nossas criações já são natureza também, aliás, sempre o foram, desde sua concepção até a produção de seus resíduos e rejeitos. 
De acordo com a abordagem espinosana, todos os seres encontram alegria quando sua plenitude de ação é aumentada e tristeza quando esta última é diminuída. Podemos estender essa compreensão aos rios que foram drasticamente alterados para a construção de usinas como Belo Monte; e a todos os povos indígenas que foram, e ainda são direta ou indiretamente afetados por gigantes equipamentos de concreto instalados no meio da floresta, pela inundação de uma grande área ecossistêmica, alterando o funcionamento das cheias e vazantes no território, transformando completamente a relação estabelecida entre pessoas e peixes nas águas bruscamente reformatadas.

Por que sair, especialmente, em defesa das crianças indígenas e de suas infâncias? Primeiramente, por seu direito à existência, porque perseverar na vida é um direito seu. O foco nas crianças indígenas se dá pela necessidade de sensibilizar para uma necessária aproximação daquilo que o projeto capitalista-colonizador sempre necessitou afastar: o espírito de coletividade, a solidariedade, a criação, o encontro das gerações, omnilateralidade, a natureza, a ludicidade, a brincadeira. Vivemos na contramão da natureza: adoecemos os rios e os mares, as comidas, o ar, adoecemos nós! Ao defender os povos originários e suas crianças, mantemos uma porta aberta para a afirmação da vida.

O exercício de constituição existencial dos infantes humanos se dá no brincar. As indígenas brincam livremente porque os adultos as entendem como seres que se constituem em conexão, e a partir de seus próprios desejos, com o que afeta, aqui e agora. Entretanto, as crianças urbanas dispõem, cada vez menos, de condições para brincar - na cidade, em casa, na escola - porque aqui elas estão destinadas à vida adulta, são, conduzidas, educadas com referência no padrão- adulto-trabalhador. Vivendo em grandes conglomerados humanos - em um tempo de produtivismo exacerbado, condições de moradia verticalizadas ou rizomáticas, perigos externos às vezes mortais - para as crianças urbanas, especialmente as das classes populares, os bons encontros com a natureza podem ser apenas acasos. Porque gozar, desfrutar das interações que a vida pode oferecer, se constituir nelas, fruir: isso não faz sentido na ordem opressora de sociedades regidas por relações de lucro e poder. Brincar não interessa à lógica do Capital. Interessa, ao contrário, que sejam sentidas e compreendidas como "Uma presença através de uma ausência" (PANCERA, 1994, p.103), em oposição ao adulto que ainda não é. 
Para redesenhar a vida, as novas gerações necessitam ser assumidas como seres da cultura e simultaneamente da natureza, com referências culturais, históricas, ambientais, espirituais muito distintas das que Ihes oferecemos na vida cotidiana, na escola. Dependemos da existência dos povos originários para aprender com eles modos mais compatíveis com o planeta. Não se trata de idealismo ingênuo, delírio ufanista, referências idílicas em relação a estes povos, não se trata de propor um retorno à aldeia. Mas da necessidade de aprender com quem sabe viver fora da imensa bolha consumista, distante (mas não à parte) da cultura vídeo maquínica, em conexão com os ventos, as marés, o fogo, as raízes. Morrendo as novas gerações indígenas, morrem culturas cuja existência se dá em harmonia com a natureza, em que as espécies coexistem sem antagonismos; em territórios não organizados pela propriedade privada, pois a terra não pertence aos indígenas, são os indígenas que pertencem à terra.

Decerto que a derrubada da sociobiodiversidade não é salutar nem aos povos indígenas, nem à própria floresta, que apenas em nossa visão ocidental os distingue. As crianças participam da sociobiodiversidade, contribuem para sua riqueza, sua condição biofílica as convoca a esse movimento de pertencimento da natureza (TIRIBA; PROFICE, 2019).

O vírus global ameaça, especialmente agora, pela mineração, pelo agronegócio, por usinas que fazem submergir não apenas as terras, a vegetação, os animais, mas etnias inteiras. Os recursos medicinais e curativos são solapados pela pandemia. As aldeias não estão isoladas, ao contrário, está dada a autorização federal para invasão de terras indígenas e livre ação dos garimpeiros. Órgãos como Instituto Brasileiro do Meio ambiente e dos Recursos Naturais Renováveis (IBAMA) e a Fundação Nacional do Índio (FUNAI) completamente desarticulados e sabotados, não mais coíbem a ação de invasores, uns latifundiários, outros também miseráveis em busca de maior fortuna. No plano da educação também os tempos andam bicudos, no que se refere à educação escolar indígena, o quadro não poderia ser de maior desmonte.

Estamos perdendo a floresta e, com ela, as culturas indígenas e suas crianças, talvez as últimas a nos indicarem um ponto de fuga em relação às mazelas decorrentes dos maus-tratos infligidos ao planeta. Negando a natureza que somos, para a qual nos fizemos surdos e mudos, negamos nossa condição de seres 
desejantes de outros seres não humanos, processos, lendas e encantados. Será impossível garantir às crianças as condições de perseverarem como seres de cultura que se constituem e se fortalecem em conexão com a natureza, se seguirmos golpeando, física e simbolicamente, a nossa própria cultura subterrânea que insiste em perseverar e emergir, ainda que no sofrimento, como tudo o que é vivo.

\section{Referências}

ABRAMOWICZ, A. Introdução - panorama atual da Educação Infantil: suas temáticas e políticas. In: ABRAMOWICZ, A.; HENRIQUES, A. C. (Org.). Educação Infantil: a luta pela infância. - Campinas, SP: Papirus, 2018. p. 13-51.

ARROYO, M. G.; VIELLA, M. A. L.; SILVA, M. R. (Org.). Trabalho infância: exercícios criativos de ser criança: haverá espaço na agenda pedagógica? Petrópolis, RJ: Vozes, 2015.

BERGAMASCHI, M.A..A criança guarani: um modo próprio de aprender. In: URQUIZA, A.M.; NASCIMENTO, A.; VIEIRA, C. (Org.). Criança indígena, diversidade cultural, educação e representações sociais. Brasília: Liber Livro, 2011. p. 131-152.

BRANDT, A. J. A criança guarani em contexto de rápidas mudanças. IN: URQUIZA, A.M.; NASCIMENTO, A.; VIEIRA, C. (Org). Criança indígena, diversidade cultural, educação e representações sociais. Brasília: Liber Livro, 2011. p. 113-130.

BRASIL. Resolução CNE ํo 2, de 15 de junho de 2012. Estabelece as Diretrizes Curriculares Nacionais para a Educação Ambiental, 2012a. Disponível em: $<$ http://conferenciainfanto.mec.gov.br/images/conteudo/iv-cnijma/diretrizes.pdff $>$ Acesso em: 15 jan. 2019

Ministério da Educação. Resolução no 1, 30 de maio de 2012. Diretrizes Nacionais para a Educação em Direitos Humanos, 2012b. Disponível em: $<$ http://portal.mec.gov.br/dmdocuments/rcp001 12.pdf> Acesso em: 15 jan. 2019.

. Secretaria de Educação Básica. Diretrizes Curriculares Nacionais para a Educação Infantil. Brasília, DF: MEC/CNE/SEB, 2009. Disponível em $<$ http://portal.mec.gov.br/index.php?option=com docman\&view=download\&alias=22 98-rceb005-09\&category slug=dezembro-2009-pdf\&ltemid=30192> Acesso em 15 jan. 2019.

. Estatuto da criança e do adolescente: Lei federal oㅜ 8069, de 13 de julho de 1990. Rio de Janeiro: Imprensa Oficial, 2002.

. Lei de Diretrizes e Bases da Educação Nacional. Lei número 9394, 20 de dezembro de 1996. 
. Constituição Federal de 1988. Promulgada em 5 de outubro de 1988. Disponível em <http://www.planalto.gov.br/ccivil 03/constituicao/constituição.htm>. Acesso em: 15 jan. 2019

CARREIRO, H. J. S.; TAVARES, M. T. G. Apresentação. In: Estudos e pesquisas com o cotidiano das infâncias e periferias urbanas. São Carlos: Pedro \& João Editores, 2018, p.23-39.

CLASTRES, Pierre, La société contre l'Etat: recherches d'anthropologie politique. Paris: Éditions de Minuit, 1974.

CRUZ, V. C. Povos e comunidades tradicionais. In: CALDART, R. S.; PEREIRA, I. B.; ALENTEJANO, P.; FRIGOTTO, G. (Org.). Dicionário da educação do campo. Rio de Janeiro/São Paulo: Escola Politécnica de Saúde Joaquim Venâncio. Expressão Popular, 2012. p. 524-600.

DAMÁSIO, A. Em busca de Espinosa: prazer e dor na ciência dos sentimentos. São Paulo, Companhia das Letras, 2004.

DELEUZE, G. Espinosa, filosofia prática. São Paulo: Escuta, 2002.

DIEGUES, A.C. (Org.). Os Saberes tradicionais e a biodiversidade no Brasil. São Paulo: Núcleo de Pesquisas sobre Populações Humanas e Áreas Úmidas Brasileiras da Universidade de São Paulo (NUPAUB-USP); Brasília: Coordenadoria da Biodiversidade do Ministério do Meio Ambiente, dos Recursos Hídricos e da Amazônia Legal (COBIO-MMA), 2001.

FEDERICI, S.; FEDERICI, S. Mulheres e caça às bruxas: da idade média aos dias atuais. São Paulo: Boitempo, 2019.

FROMM, E. The Anatomy of Human Destructiveness. New York: Holt, Rinehart \&; Winston, 1973.

GLEIZER, M. Espinoza e a afetividade humana. Rio de Janeiro: Jorge Zahar, 2005.

GOMES, A.N.R.; SILVA, R.C; DINIZ, L. Infância Indígena, escolarização e globalização: uma análise a partir da experiência das escolas indígenas em Minas Gerais. In: URQUIZA, A.M.; NASCIMENTO, A.; VIEIRA, C. (Org.). Criança indígena, diversidade cultural, educação e representações sociais. Brasília: Liber Livro, 2011. p. 227-267.

GUATTARI, F.; ROLNIK, S. Micropolítica: Cartografias do Desejo. Petrópolis, Vozes, 1986.

KEHL, M. R. Violação de direitos humanos dos povos indígenas. Disponível em $<$ https://edisciplinas.usp.br/pluginfile.php/4469887/mod_resource/content/1/Volume\% 202\%20-\%20Texto\%205\%20-

\%20Povos\%20Indi\%CC\%81 genas\%20na\%20CNV.pdf> Acesso em 20 mai. 2020. 
LANDA, B.S.L. Crianças Guarani: atividades, usos do espaço e a formação do registro arqueológico. IN: URQUIZA, A.M.; NASCIMENTO, A.; VIEIRA, C. (Org.). Criança indígena, diversidade cultural, educação e representações sociais. Brasília: Liber Livro, 2011. p. 45-74.

LATOUR, Bruno. Políticas da natureza: como fazer ciência na democracia. Bauru: Edusc. 2004.

LEROI-GOURHAN. A. Evoluções é Técnicas. O homem e a matéria. Lisboa: Edições 70,1971

MATURANA, H. Emoções e linguagem na educação e na política. Belo Horizonte: UFMG, 1998.

MATURANA, H.; VARELA, F. A árvore do conhecimento. Campinas: Editorial Psy II, 1995.

MIES, M.; SHIVA, V. Ecofeminismo: teoria, crítica y perspectivas. Barcelona: Icaria editorial, 1997.

MUNIZ, L. M. Ecologia Política: o campo de estudo dos conflitos sócio-ambientais. Revista Pós Ciências Sociais v.6, n.12, 2009. p. 181-196.

PANCERA, C. Semânticas da Infância. In: Perspectiva: A modernidade, a infância e o brincar. Florianópolis, UFSC/CED, NUF, n. 22, 1994. p. 97-104.

PEREIRA, B. E.; DIEGUES, A. C. Conhecimento de populações tradicionais como possibilidade Desenvolvimento e Meio Ambiente, n. 22, 2010. p. 37-50.

PORTO-GONÇALVES, C. W. A globalização da natureza e a natureza da globalização. $7^{a}$ ed, - Rio de Janeiro: Civilização Brasileira, 2017.

PROFICE, C. Crianças e natureza: reconectar é preciso. São Paulo: Pandorga, 2016.

PROFICE, C. Nature as a living presence: Drawings by Tupinambá and New York Children. PLoS ONE, v. 13, n. 10, 2018. p. 1-15.

PROFICE, C. SANTOS, G. H. De grumetes a Kunumys - estilos de infâncias brasileiras. História da Educação, v..21, n.53, 2017. p.307-325.

REZENDE, J.S. Crianças Indígenas de lauareté: fortalecimento das identidades e diferenças. In: URQUIZA, A.M.; NASCIMENTO, A.; VIEIRA, C. (Org.). Criança indígena, diversidade cultural, educação e representações sociais. Brasília: Liber Livro, 2011. p. 269-283.

SANTOS, B. S. Um discurso sobre as ciências. São Paulo: Cortez, 2010.

SILVA, A.L.; NUNES, A.; MACEDO, A.V.L.S. (Org.). Crianças Indígenas, Ensaios Antropológicos. São Paulo, Global, 2002. 
SILVA, A. M. M.; TIRIBA, L. (Org.). Direito ao ambiente como direito à vida: desafios para a educação em direitos humanos. São Paulo: Cortez, 2014.

SPINOZA, B. Ética. Belo Horizonte: Autêntica Editora, 2009.

TASSINARI, A. Concepções indígenas de infância no Brasil. Tellus, v.7, n. 13, 2007. p. 11-25.

TIRIBA, L. Educação infantil como direito e alegria: em busca de pedagogias ecológicas, populares e libertárias. Rio de Janeiro/São Paulo: Paz \& Terra, 2018a.

Crianças, natureza e educação infantil. Tese de Doutorado, Departamento de Educação, PUC-RIO, 2005.

TIRIBA, L.; PROFICE, C. O direito humano à interação com a natureza. In: REIS, M.; XAVIER, M. C.; SANTOS, L. (Org.). Crianças e infâncias: educação, conhecimento, cultura e sociedade. São Paulo: Annablume, 2012.p. 122-135.

TIRIBA, L.; VOLLGER, A; PEREIRA, J; CORTAT, R; SILVA, P. Brincando com a natureza, na aldeia e na cidade: em busca de uma pedagogia nossa. In: MORO, C. \& SOUZA, G. (Org.). Educação Infantil: Construção de Sentidos e Formação. Curitiba: NEPIE/UFPR, 2019. p. 195-218. Disponível em: $<$ https://issuu.com/nepie.ufpr/docs/ebook>

URQUIZA, A.M.; NASCIMENTO, A.; VIEIRA, C. (Org.). Criança indígena, diversidade cultural, educação e representações sociais. Brasília: Liber Livro, 2011.

VYGOTSKY, L. S. A formação social da mente. Rio de Janeiro: Martins Fontes, 1989.

WILSON, E. Biophilia. Massachusetts: Harvard University Press, 1984. 